Journal of Advanced Research in Fluid Mechanics and Thermal Sciences

Journal homepage: www.akademiabaru.com/arfmts.html ISSN: 2289-7879

\title{
A Fault Detection System for The Yaw Control of A HAWT Based on Neural Networking
}

\author{
Ahmed R. El-Mallawany ${ }^{1,2, *}$, Sameh Shaaban ${ }^{2}$, Aida Abdel Hafiz ${ }^{1}$ \\ Mechanical Power Engineering Department, Faculty of Engineering Mataria, Helwan University, Cairo, Egypt \\ Mechanical Engineering Department, College of Engineering and Technology, Arab Academy for Science, Technology and Maritime Transport \\ (AASTMT), Cairo, Egypt
}

\section{ARTICLE INFO}

\section{Article history:}

Received 5 May 2021

Received in revised form 4 July 2021

Accepted 10 July 2021

Available online 3 August 2021

Keywords:

HAWT; TurbSim; FAST; Neural Network; Fault Detection

\section{ABSTRACT}

The objective of the yaw control system in a horizontal axis wind turbine (HAWT) is to follow the wind direction with a minimum error. In this paper, a data driven fault detection approach of a HAWT is applied. Three simulation programs were utilized in order to model a $1.5 \mathrm{MW}$ HAWT. These programs are Fatigue, Aerodynamics, Structures, and Turbulence (FAST), TurbSim, and MATLAB. The approach is implemented under normal operating scenarios while considering different wind velocities. Different kinds of faults were applied to the system for a nacelle-yaw angle error ranging from $-10^{\circ}$ to $+20^{\circ}$. The simulation results of the Tower Top Deflection (TTD) in the time domain were transferred into frequency domain by Fast Fourier Transform (FFT). The output variables were used in order to build a Neural Networking, which will monitor the performance of the wind turbine. The built Neural Networking will also provide an early fault detection to avoid the operating conditions that lead to sudden turbine breakdown. The present work provides initial results that are useful for remote condition monitoring and assessment of a 1.5MW HAWT. The simulation results indicate that the implemented Neural Networking can achieve improvement of the wind turbine operation and maintenance level.

\section{Introduction}

Wind energy is considered as one of the fastest growing energy resources in the world. Especially after the petroleum oil crisis in the 1970s [1]. Consequently, the design, operation, and control of wind turbines is attracting more attention. The objective of the wind turbine control system is to follow the power reference; or if not possible minimize the reference error. This control of power should be done such that mechanical vibrations are kept minimal. However, it is well-known that Wind Turbines (WTs) have several different operating modes [2]. Concentrated wind gusts, rapid wind direction changes, or passage of energetic atmospheric structures can cause critical loads on the wind turbines and its blades [3]. A wind turbine benchmark model for the simulation of fault detection and accommodation schemes has been reported [4]. Different developed techniques,

\footnotetext{
* Corresponding author.

E-mail address: ahmedelmallawany@yahoo.com
}

https://doi.org/10.37934/arfmts.85.1.135142 
methodologies and algorithms for monitoring the performance of wind turbines and early fault detection to avoid wind turbines sudden breakdown have been reviewed [5]. A wind turbine model for the simulation of fault detection and accommodation schemes has been studied by Odgaard et al., [4]. The results show that different kinds of faults were included and the model can be applied on a realistic wind turbine model. A data-driven fault detection for a wind turbine was introduced to overcome the nonlinearity, unknown disturbances, and significant measured noise [6]. This datadriven fault detection scheme was studied with robust residual generators directly constructed from available process data. The effectiveness of the proposed scheme was demonstrated by the results obtained from the simulation of a wind turbine benchmark model. Condition monitoring is a tool used for early detection of faults/ failures [7]. Its main target is to minimize the number of shutdowns and maximize the productivity of the system. The main obstacles facing the designers of condition monitoring systems for wind turbines are

i. The number and type of sensors selected

ii. The effectiveness of signal processing methods associated with the selected sensors

iii. The effectiveness of fusion model design (i.e., the combination of sensors and signal processing methods which give an improved performance).

A modern $5 \mathrm{MW}$ turbine implemented in the (FAST) software has been studied [8]. The baseline feedback loop uses information from sensors as input to the pitch, torque, and yaw controllers. Actuator models for the pitch drives, generator, and yaw drive were implemented within the Simulink environment. Faults were corrupting both the actuators and sensors. Controlling the power generation in variable speed wind turbines was proposed using a high-order sliding-mode control strategy to ensure the stability in operation and impose an ideal feedback control solution despite of model uncertainties [9]. This strategy presents attractive features such as robustness to parametric uncertainties of the turbine and the generator as well as to electric grid disturbances. The strategy was validated by (FAST) code and the results show that the strategy is effective in power regulation, and the torque generator remains smooth. TurbSim, FAST, and Simulink were utilized to model the wind, mechanical and electrical parts of a wind turbine, and its controllers [10]. The results show the interaction of the main three factors affecting the operation of wind turbines. Such that the electrical disturbance may lead to tower vibration under high speed while the turbulent wind conditions and power system disturbances may cause mechanical problems.

\section{Theoretical Background}

Condition monitoring and assessment of a 1.5MW HAWT is considered in the present work. As the HAWT have a relatively high power coefficient [11]. The specifications of the investigated wind turbine are listed in Table 1.

Table 1

Specifications of the 1.5 MW HAWT

\begin{tabular}{ll}
\hline Rated rotational speed & $20 \mathrm{rpm}$ \\
\hline Number of blades & 3 blades \\
$V_{\text {cut in }}$ & $4 \mathrm{~m} / \mathrm{s}$ \\
$V_{\text {rated }}$ & $12 \mathrm{~m} / \mathrm{s}$ \\
$V_{\text {cut out }}$ & $25 \mathrm{~m} / \mathrm{s}$ \\
Blade Diameter & $70 \mathrm{~m}$ \\
Tower height & $82.39 \mathrm{~m}$ \\
Rated power & $1.5 \mathrm{MW}$ \\
\hline
\end{tabular}


The wind power is proportional to the cube the wind speed, Eq. (1), where, $P_{\text {wind }}, \rho, A$, and $v$ represent the wind power, air density, swept area, and wind velocity, respectively. Based on Betz limit, the theoretical maximum aerodynamic efficiency is 0.593 of the available wind powers [12]. Therefore, the wind turbine power $\mathrm{P}$ as a function of time $(\mathrm{t})$ is defined as shown in Eq. (2).

$P_{\text {wind }}(t)=\frac{1}{2} \rho A v^{3}(t)$

$P(t)=\frac{1}{2} \rho A C_{p}(\lambda, \theta) v^{3}(t)$

where $C_{p}$ is the power coefficient, defined in Eq. (3), which is affected by the tip speed ratio ( $\lambda$ ), and the blade pitch angle $(\theta)$. The constants $C_{1}, C_{2}, C_{3}, C_{4}, C_{5}$, and $C_{6}$ equal $0.5176,116,0.4,5,21$, and 0.0068 , respectively $[13,14]$. The tip speed ratio is considered as the ratio of the blade tip tangential speed, and the actual wind velocity, Eq. (4).

$C_{p}(\lambda, \theta)=C_{1}\left(\frac{C_{2}}{\lambda_{I}}-C_{3} \theta-C_{4}\right) \exp \left(\frac{-C_{5}}{\lambda_{i}}\right)+C_{6} \lambda$

where,

$\frac{1}{\lambda_{I}}=\left(\frac{1}{\lambda+0.08 \theta}-\frac{0.035}{\theta^{3}+1}\right)$

$\lambda=\frac{\omega(t) r}{v(t)}$

where $\omega(\mathrm{t})$ is the rotational speed, and $\mathrm{r}$ is the blade radius. Nowadays, YAW, and blade pitch control systems are commonly used in HAWTs. The main target of the YAW control is to ensure that the rotor is facing the direction of the upcoming wind by adjusting the nacelle of the turbine. The blade pitch control is used to adjust the angle $(\theta)$ of the blade. As shown in Eq. (2), $C_{p}$ is function of the angle $(\theta)$, and the tip speed ratio $(\lambda)$. The maximum value of the $C_{p}$ is achieved at an angle $(\theta)$ equal to zero, as shown in Figure 1.

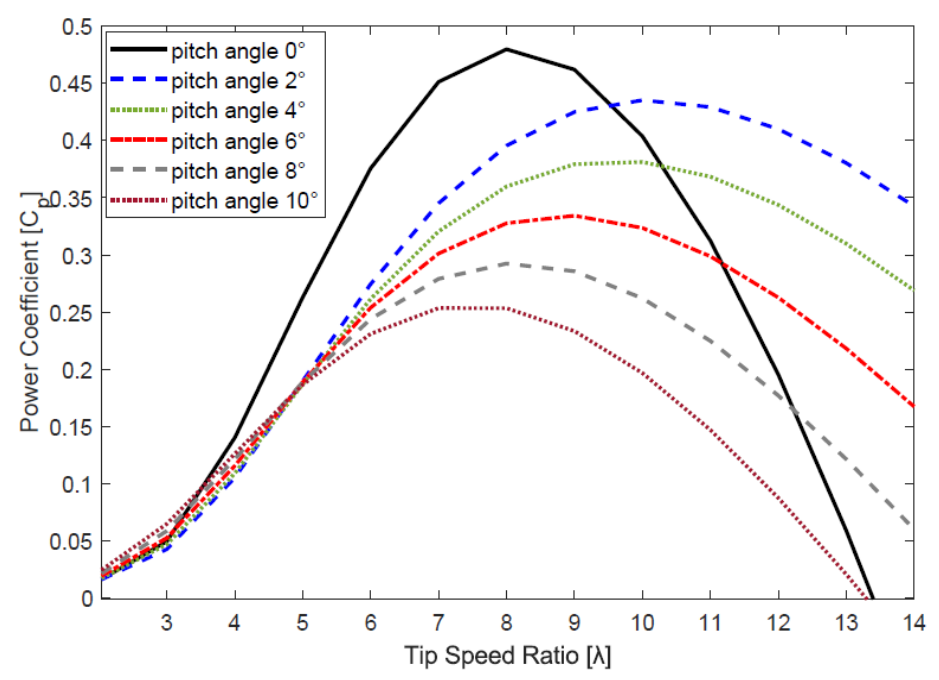

Fig. 1. Power coefficient of the 1.5 MW HAWT 
The tip speed ratio is plotted against power coefficient for a blade pitch angle of $\left(0^{\circ}\right)$, as shown in Figure 2. The maximum value of the power coefficient is achieved at a tip speed ratio of 8.1. The target of the control system is to achieve a maximum value for the $C_{p}$ between the cut-in velocity $V_{\text {cut in, }}$ and the rated wind velocity $V_{\text {rated. }}$. Meanwhile, for a wind conditions between $V_{\text {rated, }}$ and the cut-out wind velocity $V_{\text {cut out, }}$ the target of the control system is to minimize the $C_{p}$ value. This is achieved by changing the blade pitch angle. For any specific operating wind velocity above $V_{\text {rated, }}$ there is a corresponding tip speed ratio since the rotor speed $\omega(t)$ is fixed at its rated value, Eq. (3). Figure 3 shows the relation between the blade pitch angle, and the power coefficient while using wind speeds of $12 \mathrm{~m} / \mathrm{s}, 14 \mathrm{~m} / \mathrm{s}$, and $18 \mathrm{~m} / \mathrm{s}$.

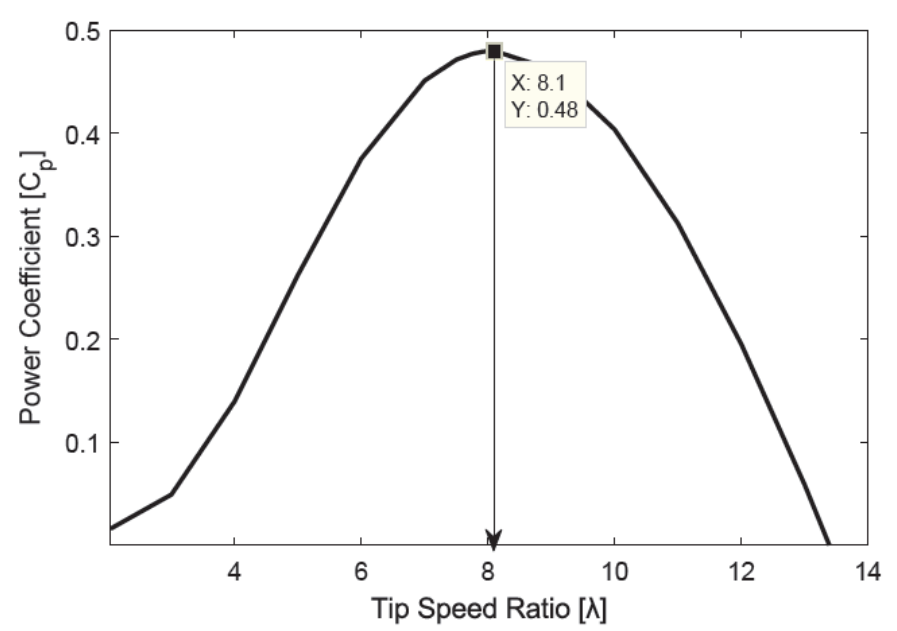

Fig. 2. Power coefficient of $1.5 \mathrm{MW}$ HAWT at a Blade pitch angle $\left(0^{\circ}\right)$

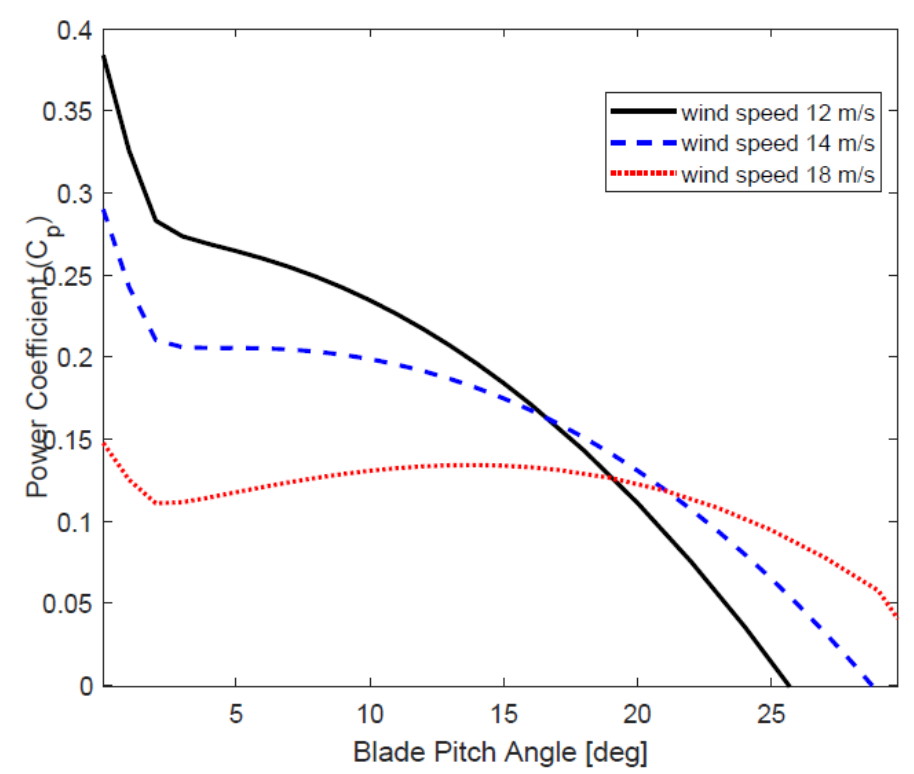

Fig. 3. Blade pitch angle Vs. Power coefficient under different wind velocities 


\section{Methodology}

The FAST (Fatigue, Aerodynamics, Structures, and Turbulence) code is a comprehensive aeroelastic simulator capable of predicting both the extreme and fatigue loads of three-bladed horizontal-axis wind turbines (HAWTs) [15]. FAST has different control methods, such as: Blade Pitch Control, and Nacelle Yaw Control. The TurbSim stochastic inflow turbulence code was used to provide a numerical simulation of a full-field flow that contains bursts of coherent turbulence that reflect the proper spatiotemporal turbulent velocity field relationships seen in instabilities associated with nocturnal boundary layer flows. Its purpose is to provide the ability to drive the FAST design code simulations of advanced turbine designs with simulated inflow turbulence environments that incorporate many of the important fluid dynamic features known to adversely affect the turbine aeroelastic response and loading [16].The present work aims at collecting more data that contain different combinations of normal operating conditions and cover complete regimes of WTs in order to train a more accurate health reference model with better generalization ability. A FAST code of a 1.5 MW wind turbine with TurbSim code has been used to simulate the system. The objective of the present study is to model the system under normal operating scenarios while considering the importance of different wind velocities. Then, applying nacelle-yaw faults of $-10^{\circ}, 10^{\circ}$, and $20^{\circ}$. A Fast Fourier Transform (FFT) algorithm is used to convert the output data from its original time domain to a representation in the frequency domain, Eq. (5).

$x(k)=\sum_{n=0}^{N-1} x(n) \exp \left(-j 2 \pi \frac{n k}{N}\right)=\sum_{n=0}^{N-1} x(n) W_{N}^{n k}$

where, $x(k)$ :is the $\mathrm{k}^{\text {th }}$ harmonic $(\mathrm{k}=0 \ldots \mathrm{N}-1), x(n)$ : is the $\mathrm{n}^{\text {th }}$ input sample $(\mathrm{n}=0 \ldots \mathrm{N}-1)$, and $W_{N}:$ is shorthand for $\exp \left(\frac{-j 2 \pi}{N}\right)$.The Neural network, Eq. (6), which is an artificial network, composed of neurons, and nodes. This network can be used for predictive modeling, adaptive control, and applications where they can be trained via a dataset. By self-learning, the networks can derive conclusions from complex and related set of information

$a=\sigma\left(\sum_{i} \omega_{i} x_{i}+b\right)$

where, $x_{i}$ : input vector, $b$ : bias, $\sigma$ :activation function, and $\omega_{i}$ : synapse weight associated with each input.

\section{Results and Discussion}

As wind turbine grow in size, the output power, and structural loads increase. These structural loads lead to undesirable performance, and early failure. A fault detection strategy to suppress wind turbine tower vibration is presented. Normally, wind turbines are subjected to different wind profiles. As the average wind speed for the majority of the international wind farms is $15 \mathrm{~m} / \mathrm{s}$, the 1.5MW HAWT has been simulated under different wind profiles in the range from $7 \mathrm{~m} / \mathrm{s}$ to $18 \mathrm{~m} / \mathrm{s}$ [17].

Results of the tower top deflection Side to Side were analyzed by Fast Fourier Transform (FFT), as shown in Figure 4. At the beginning, a $7 \mathrm{~m} / \mathrm{s}$ wind velocity was applied to the system as in Figure 4(a). The magnitude of amplitude spectrum under normal operating conditions is 0.039 at $5.67 \mathrm{~Hz}$, and reached 0.06 while applying Yaw error of $20^{\circ}$ at the same frequency. Results show that the magnitude of the amplitude spectrum of Yaw error $20^{\circ}$ is 1.5 times that under normal conditions. The $1.5 \mathrm{MW}$ 
HAWT was tested under other different wind velocities. The magnitude of the amplitude spectrum of yaw error $20^{\circ}$ reached $1.28,1.36$, and 1.17 compared to that of the normal conditions while applying $9 \mathrm{~m} / \mathrm{s}, 14 \mathrm{~m} / \mathrm{s}$, and $18 \mathrm{~m} / \mathrm{s}$, respectively.

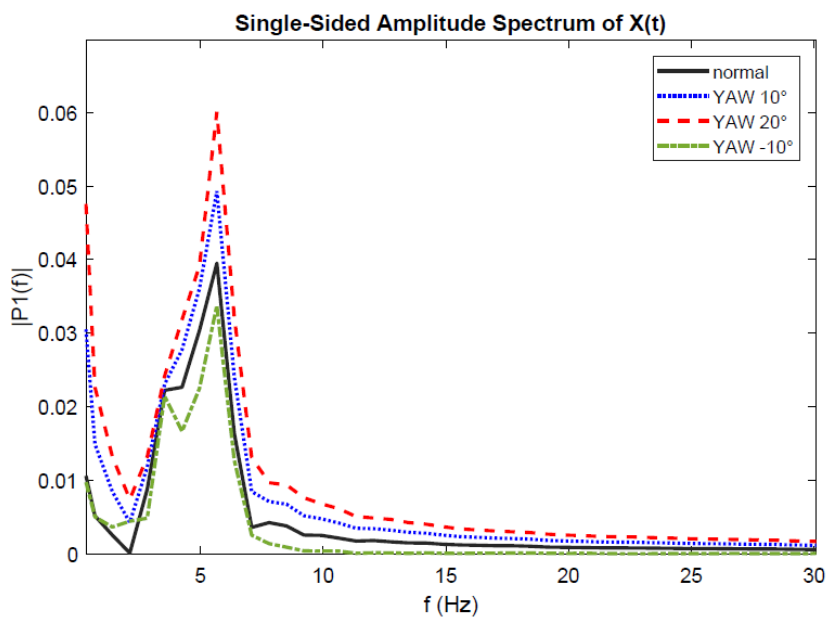

(a)

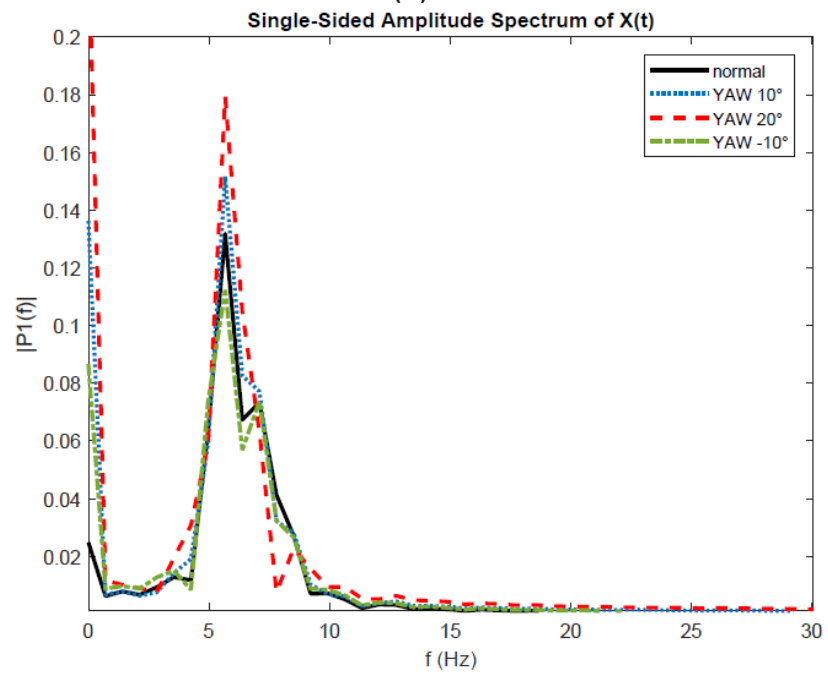

(c)

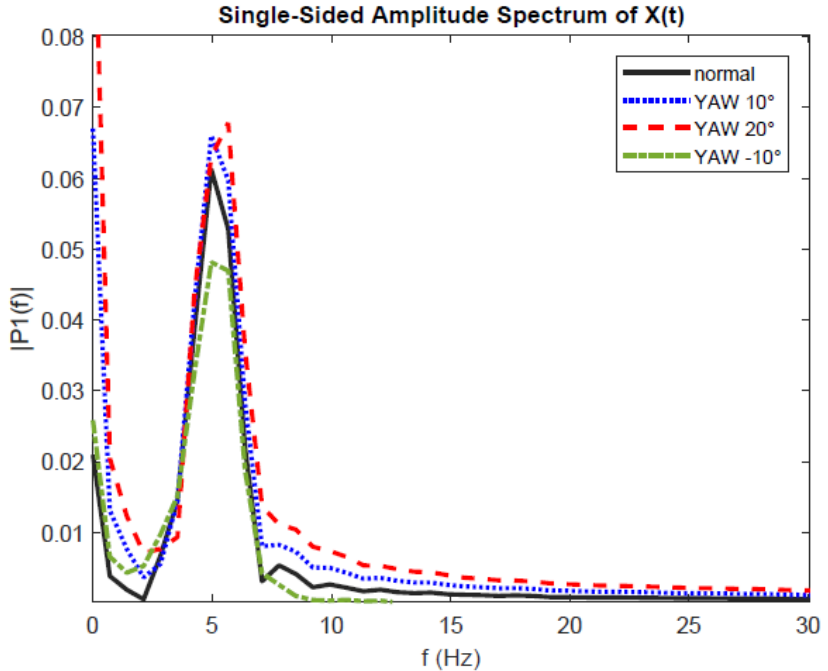

(b)

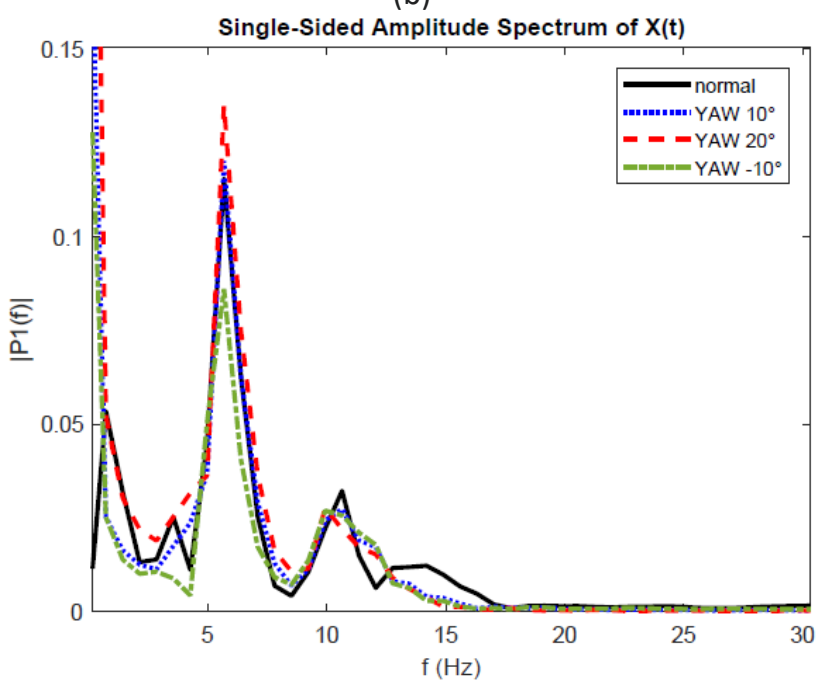

(d)

Fig. 4. Effect of YAW error on the tower top deflection SS (frequency domain) (a)Wind speed $7 \mathrm{~m} / \mathrm{s}$, (b) Wind speed $9 \mathrm{~m} / \mathrm{s}$, (c) Wind speed $14 \mathrm{~m} / \mathrm{s}$, (d) Wind speed $18 \mathrm{~m} / \mathrm{s}$

A neural network was built to identify the faults in the HAWT. One of its most important features is that a neural network has a learning ability. This ability allows it to learn its environment and improve its performance. Neural networks consist of three layers, an input layer, an intermediate layer, and an output layer. It is considered that the Feed-forward neural networks are the mostly encountered type of artificial neural networks, and applied to many diverse fields [18]. A feed forward back propagation was used. The results show that the best validation performance of the cycle is 0.01122 . 


\section{Conclusion}

A fault detection strategy to suppress wind turbine tower vibration and prevent early turbine failure was introduced. The results of the nacelle-yaw angle error ranging from $-10^{\circ}$ to $+20^{\circ}$ of the Tower Top Deflection under different wind speed conditions were transferred from time domain to frequency domain by FFT. While applying a $7 \mathrm{~m} / \mathrm{s}$ wind speed, the magnitude of the amplitude spectrum of Yaw error $20^{\circ}$ was 1.5 times compared to that under normal conditions. All results in the frequency domain were utilized to build a neural network. The neural network got a best validation performance of 0.011. As a result, it is recommended to use the Tower Top Deflection as an indicator for fault detection in wind turbines, and measure its value by a laser vibrometer.

\section{References}

[1] Radzi, Abdul Qoiyum Mohd, and Noorazizi Mohd Samsuddin. "Design optimization of savonius wind turbine using CFD-particle swarm optimization with power flow validation experimentally." CFD Letters 12, no. 10 (2020): 27-39. https://doi.org/10.37934/cfdl.12.10.2739

[2] Jiang, Guoqian, Ping Xie, Haibo He, and Jun Yan. "Wind turbine fault detection using a denoising autoencoder with temporal information." IEEE/ASME Transactions on Mechatronics 23, no. 1 (2017): 89-100. https://doi.org/10.1109/TMECH.2017.2759301

[3] Kelley, Neil Davis, Bonnie J. Jonkman, George N. Scott, and Yelena L. Pichugina. Comparing pulsed Doppler LIDAR with SODAR and direct measurements for wind assessment. No. NREL/CP-500-41792. National Renewable Energy Lab. (NREL), Golden, CO (United States), 2007.

[4] Odgaard, Peter Fogh, Jakob Stoustrup, and Michel Kinnaert. "Fault tolerant control of wind turbines-a benchmark model." IFAC Proceedings Volumes 42, no. 8 (2009): 155-160. https://doi.org/10.3182/20090630-4-ES-2003.00026

[5] Hameed, Z., Y. S. Hong, Y. M. Cho, S. H. Ahn, and C. K. Song. "Condition monitoring and fault detection of wind turbines and related algorithms: A review." Renewable and Sustainable Energy Reviews 13, no. 1 (2009): 1-39. https://doi.org/10.1016/j.rser.2007.05.008

[6] Yin, Shen, Guang Wang, and Hamid Reza Karimi. "Data-driven design of robust fault detection system for wind turbines." Mechatronics 24, no. 4 (2014): 298-306. https://doi.org/10.1016/i.mechatronics.2013.11.009

[7] Márquez, Fausto Pedro García, Andrew Mark Tobias, Jesús María Pinar Pérez, and Mayorkinos Papaelias. "Condition monitoring of wind turbines: Techniques and methods." Renewable Energy 46 (2012): $169-178$. https://doi.org/10.1016/j.renene.2012.03.003

[8] Odgaard, Peter F., and Kathryn E. Johnson. "Wind turbine fault detection and fault tolerant control-an enhanced benchmark challenge." In 2013 American Control Conference, pp. 4447-4452. IEEE, 2013. https://doi.org/10.1109/ACC.2013.6580525

[9] Beltran, Brice, Tarek Ahmed-Ali, and Mohamed El Hachemi Benbouzid. "High-order sliding-mode control of variable-speed wind turbines." IEEE Transactions on Industrial Electronics 56, no. 9 (2008): 3314-3321. https://doi.org/10.1109/TIE.2008.2006949

[10] Fadaeinedjad, Roohollah, Mehrdad Moallem, and Gerry Moschopoulos. "Simulation of a wind turbine with doubly fed induction generator by FAST and Simulink." IEEE Transactions on Energy Conversion 23, no. 2 (2008): 690-700. https://doi.org/10.1109/TEC.2007.914307

[11] Khattak, M. A., N. S. Mohd Ali, N. H. Zainal Abidin, N. S. Azhar, and M. H. Omar. "Common Type of Turbines in Power Plant: A Review." Journal of Advanced Research in Applied Sciences and Engineering Technology 3, no. 1 (2016): $77-$ 100.

[12] Takey, Mohamed, Tholudin Mat Lazim, Iskandar Shah Ishak, N. A. R. Nik Mohd, and Norazila Othman. "Computational Investigation of a Wind Turbine Shrouded with a Circular Ring." CFD Letters 12, no. 10 (2020): 40 51. https://doi.org/10.37934/cfdl.12.10.4051

[13] Li, Shanzhi, Haoping Wang, Yang Tian, and Abdel Aitouche. "A RBF neural network based MPPT method for variable speed wind turbine system." IFAC-PapersOnLine 48, no. $21 \quad$ (2015): $244-250$. https://doi.org/10.1016/j.ifacol.2015.09.535

[14] Lio, Wai Hou Alan. Blade-pitch control for wind turbine load reductions. Springer, 2018. https://doi.org/10.1007/978-3-319-75532-8

[15] Jonkman, Jason M., and Marshall L. Buhl Jr. "FAST user's guide." Golden, CO: National Renewable Energy Laboratory 365 (2005): 366. 
[16] Jonkman, Bonnie J., and M. L. Buhl Jr. TurbSim User's Guide: Revised February 2007 for Version 1.21. No. NREL/TP500-41136. National Renewable Energy Lab.(NREL), Golden, CO (United States), 2007. https://doi.org/10.2172/903075

[17] Kunya, Bashir Isyaku, Clement Olaloye Folayan, Gyang Yakubu Pam, Fatai Olukayode Anafi, and Nura Mu'az Muhammad. "Performance study of Whale-Inspired Wind Turbine Blade at Low Wind Speed Using Numerical Method." CFD Letters 11, no. 7 (2019): 11-25.

[18] Sazli, Murat H. "A brief review of feed-forward neural networks." Communications Faculty of Sciences University of Ankara Series A2-A3 Physical Sciences and Engineering 50, no. 1 (2006): 11-17. https://doi.org/10.1501/commua1$\underline{20000000026}$ 